\title{
Nuclear Engineering Enrollments and Degrees Survey, 2007 Data
}

\section{SURVEY UNIVERSE}

The survey includes degrees granted between September 1, 2006, and August 31, 2007, and fall 2007 enrollments. Thirty-one academic programs reported having nuclear engineering programs during 2007 , and data was obtained for all thirty-one.

\section{DEGREE DATA}

Bachelor's Degrees. The number of B.S. degrees granted in 2007 by nuclear engineering programs increased for the fourth consecutive year and was $19 \%$ greater than in 2006. (See Table 1.) The increase in 2007 was less in both percentage and absolute terms than the increase in 2006. The number of B.S. degrees in 2007 was the highest reported since 1995, but still below the number of B.S. degrees granted annually from the early 1970s through the early 1990s. Nuclear engineering majors accounted for $96 \%$ of all B.S. degrees. (See Table 2.)

Graduate Degrees. The number of master's degrees granted in 2007 increased for the fifth consecutive year and was $6 \%$ greater than in 2006. This is the highest number of masters' degrees reported since 1996 but still below the numbers granted annually from the early 1970s through the early 1990s. The number of doctorate degrees increased substantially in 2007 reflecting several years of growth in graduate student enrollments. (See Table 1.) Nuclear engineering majors accounted for almost all of the M.S. and Ph.D. degrees. (See Table 2.)

Table 1. Nuclear Engineering Degrees, 2000-2007

\begin{tabular}{cccc} 
& \multicolumn{3}{c}{ Degrees } \\
\cline { 2 - 4 } Year & B.S. & M.S. & Ph.D. \\
\hline 2007 & 413 & 227 & 89 \\
2006 & 346 & 214 & 70 \\
2005 & 268 & 171 & 74 \\
2004 & 219 & 154 & 75 \\
2003 & 166 & 132 & 78 \\
2002 & $195^{\star}$ & 130 & 67 \\
2001 & 120 & 145 & 80 \\
2000 & 159 & 133 & 74
\end{tabular}

*Three programs were discontinued/out-of-scope after 2002 and not included in the 2003 survey. These three programs reported a total of 17 B.S. degrees in 2002.

Table 2. Nuclear Engineering Degrees, 2007, by Curriculum

\begin{tabular}{lrrr}
\multicolumn{1}{c}{ Curriculum } & B.S. & M.S. & Ph.D. \\
\hline Nuclear Engineering Major & 397 & 225 & 88 \\
Nuclear Engineering Option & 16 & 2 & 1
\end{tabular}




\section{ENROLLMENTS AND SHORT-TERM OUTLOOK FOR DEGREE TRENDS}

Undergraduate Students. In 2007, the reported enrollment of junior and senior nuclear engineering undergraduate students was over 1,300. Undergraduate enrollments have increased annually since 2000 when the lowest number (approximately 460) was reported in the time series. The increase in enrollments in 2007 was about one-fourth the increase reported in 2006. Enrollments are still below the numbers reported from the mid 1970s through the early 1990s. The continued increase in junior/senior undergraduate enrollments over the last two years indicates that the number of B.S. degrees is likely to continue to increase in the next couple of years.

Graduate Students. Graduate student enrollment reported in 2007 was almost 1,100, an increase of about 4\% over 2006 (a slightly lower percentage increase than reported in 2006 over 2005). This is 45\% greater than in 2000 and 2001 (when the lowest enrollment numbers were reported in the time series). However, the graduate enrollments are still well below the numbers reported from the mid 1970s through the mid 1990s. The continued increase in graduate enrollment indicates that the number of M.S. degrees should continue to increase for the next few years. It is also likely that the number of Ph.D. degrees will continue to increase for the next several years.

\section{CITIZENSHIP, GENDER, AND RACE/ETHNICITY OF DEGREE RECIPIENTS (TABLE 3.)}

Citizenship. Less than $1 \%$ of B.S. degree recipients were non-U.S. citizens. Among M.S. degree recipients, $19 \%$ were non-U.S. citizens; and for Ph.D. degree recipients, $44 \%$ were non-U.S. citizens. The higher percentages of non-U.S. citizens among graduate degree recipients is a continuation of a long-term trend common across graduate engineering academic programs.

Gender. Females comprised $23 \%$ of the B.S. degree recipients, $19 \%$ of the M.S. degree recipients, and $10 \%$ of the Ph.D. recipients.

Race/Ethnicity. Among the B.S. degree recipients, one out of eight (12.5\%) of the U.S. citizens were members of minority groups. Among the M.S. degree recipients, over $11 \%$ of the U.S. citizens were members of minority groups. Among the Ph.D. degree recipients, $10 \%$ of the U.S. citizens were members of minority groups.

Table 3. Citizenship, Gender, and Race/Ethnicity of Degree Recipients, 2007

\begin{tabular}{lrrrrrr} 
& \multicolumn{2}{c}{ B.S. } & \multicolumn{2}{c}{ M.S. } & \multicolumn{2}{c}{ Ph.D. } \\
\cline { 2 - 7 } & Female & Male & Female & Male & Female & Male \\
\cline { 2 - 7 } Non-U.S. Citizens & 2 & 2 & 15 & 28 & 3 & 36 \\
U.S. Citizens & & & & & & \\
$\quad$ African/Black Americans & 4 & 3 & 1 & 2 & 0 & 0 \\
American Indians/Native Americans & 0 & 0 & 0 & 0 & 0 & 0 \\
Asian/Pacific Island Americans & 6 & 15 & 4 & 4 & 0 & 3 \\
Hispanic Americans & 6 & 17 & 0 & 10 & 0 & 2 \\
White/Caucasian Americans & 73 & 278 & 22 & 129 & 6 & 37 \\
Other or Unknown & 4 & 3 & 2 & 10 & 0 & 2 \\
Totals & 95 & 318 & 44 & 183 & 9 & 80
\end{tabular}


Table 4. Nuclear Engineering Degrees, 2007, by Academic Institution (alphabetical by state and then university)

Degrees

Sept. 1, 2006 - Aug. 31, 2007

\begin{tabular}{|c|c|c|c|c|}
\hline State & Name of Institution & B.S. & M.S. & Ph.D. \\
\hline CA & University of California, Berkeley & 15 & 10 & 8 \\
\hline FL & University of Florida & 17 & 14 & 2 \\
\hline GA & Georgia Institute of Technology & 14 & 28 & 6 \\
\hline ID & Idaho State University & 6 & 1 & 1 \\
\hline $\mathrm{IL}$ & University of Illinois at Urbana-Champaign & 20 & 13 & 8 \\
\hline IN & Purdue University & 39 & 7 & 9 \\
\hline KS & Kansas State University & 8 & 1 & 0 \\
\hline MA & Massachusetts Institute of Technology & 20 & 25 & 12 \\
\hline MA & University of Massachusetts, Lowell & 5 & 0 & 0 \\
\hline MD & University of Maryland & 0 & 1 & 0 \\
\hline ME & University of Maine & 1 & 0 & 0 \\
\hline MI & University of Michigan & 17 & 16 & 7 \\
\hline MO & Missouri University of Science and Technology & 25 & 3 & 0 \\
\hline MO & University of Missouri - Columbia & 0 & 4 & 8 \\
\hline NC & North Carolina State University & 22 & 13 & 3 \\
\hline NM & University of New Mexico & 7 & 3 & 1 \\
\hline NV & University of Nevada, Las Vegas & 0 & 0 & 0 \\
\hline NY & Rensselaer Polytechnic Institute & 46 & 1 & 2 \\
\hline NY & United States Military Academy & 17 & 0 & 0 \\
\hline $\mathrm{OH}$ & Air Force Institute of Technology & 0 & 6 & 1 \\
\hline $\mathrm{OH}$ & Ohio State University & 0 & 13 & 3 \\
\hline $\mathrm{OH}$ & University of Cincinnati & 0 & 3 & 0 \\
\hline OR & Oregon State University & 20 & 2 & 1 \\
\hline PA & Pennsylvania State University & 36 & 13 & 4 \\
\hline SC & South Carolina State University & 1 & 0 & 0 \\
\hline SC & University of South Carolina & 0 & 2 & 0 \\
\hline TN & University of Tennessee & 22 & 10 & 1 \\
\hline $\mathrm{TX}$ & Texas A\&M University & 24 & 9 & 2 \\
\hline $\mathrm{TX}$ & University of Texas & 3 & 3 & 4 \\
\hline UT & University of Utah & 0 & 4 & 0 \\
\hline WI & University of Wisconsin & 28 & 22 & 6 \\
\hline & TOTALS: & 413 & 227 & 89 \\
\hline
\end{tabular}


Prepared by: Analysis and Evaluation Group, Science Education Programs, Oak Ridge Institute for Science and Education, March 2008.

This document was prepared for U.S. Nuclear Regulatory Commission by the Oak Ridge Institute for Science and Education (ORISE) through an interagency agreement with the U.S. Department of Energy (DOE). ORISE is managed by Oak Ridge Associated Universities under DOE contract number DE-AC05-06OR23100.

The Oak Ridge Institute for Science and Education (ORISE) is a U.S. Department of Energy institute focusing on scientific initiatives to research health risks from occupational hazards, assess environmental cleanup, respond to radiation medical emergencies, support national security and emergency preparedness, and educate the next generation of scientists. ORISE is managed by Oak Ridge Associated Universities.

All opinions expressed in this report are the author's and do not necessarily reflect the policies and views of the U.S. Nuclear Regulatory Commission, the U.S. Department of Energy, or the Oak Ridge Institute for Science and Education or any of their employees. Nor does it necessarily reflect the policies and views of the sponsoring institutions of Oak Ridge Associated Universities. 